\title{
Fatty acid levels in the muscle tissue of eight beef cattle breeds
}

\author{
Pavel Suchý ${ }^{1}$ Eva Straková ${ }^{2}$, Tomáš Karel ${ }^{3}$, Ivan Herzig² \\ ${ }^{1}$ University of Veterinary and Pharmaceutical Sciences Brno, Faculty of Veterinary Hygiene and Ecology, \\ Department of Animal Husbandry and Animal Hygiene, Brno, Czech Republic \\ ${ }^{2}$ University of Veterinary and Pharmaceutical Sciences Brno, Faculty of Veterinary Hygiene and Ecology, \\ Department of Animal Nutrition, Brno, Czech Republic \\ ${ }^{3}$ University of Economics in Prague, Faculty of Information Technology and Statistics, Department of Statistics \\ and Probability, Prague, Czech Republic \\ Received December 11, 2017 \\ Accepted June 27, 2018
}

\begin{abstract}
The objective of the study was to compare the chemical composition and fatty acid profile in ten clinically healthy bulls of similar weight from eight meat cattle breeds. The animals were raised by extensive grazing under the same geographical conditions. Significant differences were observed between the monitored genotypes in terms of the dry matter content, nitrogenous matter and fats $(P \leq 0.05)$ in the musculus longissimus thoracis. The concentration of fats ranged from $68.5 \pm 18.81 \mathrm{~g}$ (Galloway cattle) to $171.6 \pm 43.3 \mathrm{~g}$ (Aberdeen Angus) per kg of dry matter. The total content of unsaturated fatty acids ranged from $20.0 \pm 2.25 \mathrm{~g}$ (Aberdeen Angus) to $42.4 \pm 7.87$ $\mathrm{g}$ (Gascon); the total sum of monounsaurated fatty acids ranged from 17.0 $\pm 2.26 \mathrm{~g}$ (Aberdeen Angus) to $33.8 \pm 3.61 \mathrm{~g}$ (Gascon); and the total sum of polyunsaturated fatty acids ranged from $3.0 \pm 1.42 \mathrm{~g}$ (Aberdeen Angus) to $5.1 \pm 3.99 \mathrm{~g}$ (Limousin) per $100 \mathrm{~g}$ of fat. The total content of $\mathrm{n}-6$ fatty acids ranged from $2.4 \pm 1.28 \mathrm{~g}$ (Aberdeen Angus) to $4.2 \pm 3.59 \mathrm{~g}$ (Limousin) and the total content of $\mathrm{n}-3$ fatty acids from $0.5 \pm 0.16 \mathrm{~g}$ (Salers) to $1.1 \pm 0.04 \mathrm{~g}$ (Gascon) per $100 \mathrm{~g}$ of fat. The properties we studied may predict the biological, dietetic, and culinary value of the meat.
\end{abstract}

Musculus longissimus thoracis, MUFA, PUFA, n-6 PUFA, n-3 PUFA

Along with vegetable oils, lipid sources in human nutrition also include fats of animal origin. Findings regarding the presence of fatty acids in vegetable and animal fats have nutritional, dietary and health implications for both people and animals. These effects include the physiological functions of fats in the living organism as well as the functions of individual fatty acids (FA) in the study of diets and in the prevention and treatment of diseases related to a temporary deficiency or increased intake. In this regard, attention is also given to the lipid component in beef (Scollan et al. 2006), where the need to increase the ratio of n-3 polyunsaturated fatty acids (PUFA) has been emphasized (Griel et al. 2006; Kris-Etherton 2007).

It is generally accepted that the concentration of FA in the meat of food animals significantly depends on the content of their diet (Aldai et al. 2008). Several authors (Enser et al. 1998; Duynisveld et al. 2006; Ponnampalam et al. 2006; Garcia et al. 2008; Smith et al. 2009; Daley et al. 2010; Yüksel et al. 2012; Turner et al. 2015) have studied the presence of FA in beef in relation to the diet. These studies compared diets based on grazing and grain-fed beef. Grazing increased the amount of the precursors of vitamins $\mathrm{A}$ and $\mathrm{E}$, as well as antioxidants such as glutathione and superoxide dismutase (Daley et al. 2010). In particular, vitamin E maintains the PUFA concentration in beef and contributes to ensuring its quality during processing (Wood et al. 2004). Calf meat on pasture had a higher percentage of saturated fatty acids (SFA), PUFA and n-3 PUFA and a lower percentage of intramuscular fat, monounsaturated fatty acids (MUFA), and n-6 PUFA than animals that were fed with corn while grazing or fed a dose of corn, soybean

Address for correspondence:

Prof. Ing. Eva Straková, Ph.D.

University of Veterinary and Pharmaceutical Sciences Brno

Faculty of Veterinary Hygiene and Ecology, Department of Animal Nutrition

Palackého tř. 1946/1, 61242 Brno, Czech Republic 
and alfalfa (Garcia et al. 2008). Yüksel et al. (2012) discovered that a diet based on grazing had a favourable impact on the FA profile in meat. However, the resulting meat was darker and tougher.

The relationships between cattle breeds, their nutrition, the presence of fatty acids in intramuscular fat and the quality of meat have been studied by various researchers (Holló et al. 2001; Dannenberger et al. 2003; Raes et al. 2003; Garcia et al. 2008; Xie et al. 2012; Liu et al. 2015). For example, Garcia et al. (2008) report that the diet had a greater influence on the composition of the fatty acids of intramuscular fat than the breed. In three breeds (Holstein, Simmental, and Chinese LongDong Yellow Cattle), Liu et al. (2015) proved that the presence of fatty acids differed in fat of the musculus longissimus thoracis and in kidney fat. In contrast, Holló et al. (2001) stated that the proportion of saturated, mono- and polyunsaturated FA were not significantly influenced by the breed (Hungarian Simmental, Holstein-Friesian) or by live weight.

Intramuscular fat in beef is very important in terms of taste and tenderness; especially its intercellular ratio, which is divided between muscle fibre in vein-like patterns and forms the so-called marbled meat (Steinhauser et al. 2000). Lipophilic substances, which are released with heat and contribute to the meat's smell and taste (Ingr 2011), are contained in the muscle fat. Jiang et al. (2011) observed the effect of fatty acids, noting a negative influence on the meat's taste for eicosapentaenoic acids (C20:5n3).

Literary data on the presence of FA in the fat of modern beef cattle breeds are hard to find, and a comparison of several breeds with the same diet, same husbandry practices, and in a single location is very rarely done. The presented work should contribute to existing knowledge and attest whether different genotypes of cattle raised by extensive grazing under the same geographical conditions influence the chemical composition of the fat component (especially in relation to the presence of individual groups of FA) in the muscles of contemporary breeds.

\section{Materials and Methods}

The subject of observation was eight beef cattle breeds recognized in the Czech Republic: Aberdeen Angus (AA), Blonde d'Aquitaine (BA), Limousin (Lim), Gascon cattle (Gas), Meat Simmental (MS), Salers (Sal), Galloway cattle (Gall) and Czech multi-colored (Ćs). Animals of the selected breeds were raised in the same region of Southern Bohemia (Křišt'anov) by extensive grazing. Their diet was based on the intake of grasslands, and their winter diet consisted of hay and straw.

Ten clinically healthy bulls of similar weight between the ages of 16 to 18 months were chosen from each beef cattle breed. After slaughtering, a 500-g muscle sample was taken from the musculus longissimus, pars thoracis. The samples were taken from the left half of the body between areas 1 to 10 of the thoracic vertebrae, then the samples were chilled, frozen and gradually analyzed. The muscle samples were provided by the producer ZEFA Volary, Czech Republic.

The dry matter, nitrogenous matter, fat, gross energy (AOAC 2006) and fatty acids were determined in a laboratory. The muscle sample was homogenized, dried at $105^{\circ} \mathrm{C}$ under prescribed conditions, and the dry matter was determined. The content of nitrogen was determined using the Kjeldahl method on a Buchi analyzer (Centec automatika, Czech Republic), and the content of nitrogenous matter (crude protein) was calculated by multiplying the value of nitrogen by the coefficient of 6.25. Fat was determined by the ANKOMXT10 Fat Analyzer (O.K. SERVIS BioPro, Czech Republic). Combusted heat was determined by a combusted sample in the calorimetric bomb in an oxygen atmosphere in the Leco (USA) calorimeter. The extraction of fat from the muscle to determine fatty acids was performed according to Hara and Radin (1978). In addition, the standard CSN EN ISO 129661, 12966-2 was used. Fatty acid esters were detected by gas chromatography using a Gas Chromatograph GC2010 analyzer (Shimadzu, Japan) with a flame ionisation detector and evaluated in the GC PostRun program. Some fatty acids in the muscle sample reached very low values below the detection limit, therefore only certain selected fatty acids were monitored. Samples were converted to the content of the given fatty acid in the sample $(\mathrm{g} / 100 \mathrm{~g}$ of fat $)$.

To ensure more accurate reproducibility, all the results are presented in muscle dry matter ( $\mathrm{g} / \mathrm{kg}$ of dry matter). The obtained results were processed by the statistical program Unistat CZ version 5.6 for Excel, in which the mean values and their differences were evaluated by multiple comparison by Tukey-HSD test at the significance level of $P \leq 0.05$. 


\section{Results}

Presence of essential nutrients in the muscle

The dry matter of muscle in the eight monitored breeds of bulls (Table 1) was determined at a range from $245.2 \pm 17.64 \mathrm{~g}$ (Gall) to $277.6 \pm 11.63 \mathrm{~g}$ (AA) per $\mathrm{kg}$, which proves a positive correlation $(\mathrm{r}=+0.922 ; P<0.05)$ with the fat content, whose concentration ranges from $68.5 \pm 18.81 \mathrm{~g}$ (Gall) to $171.6 \pm 43.30 \mathrm{~g}(\mathrm{AA})$ per $\mathrm{kg}$.

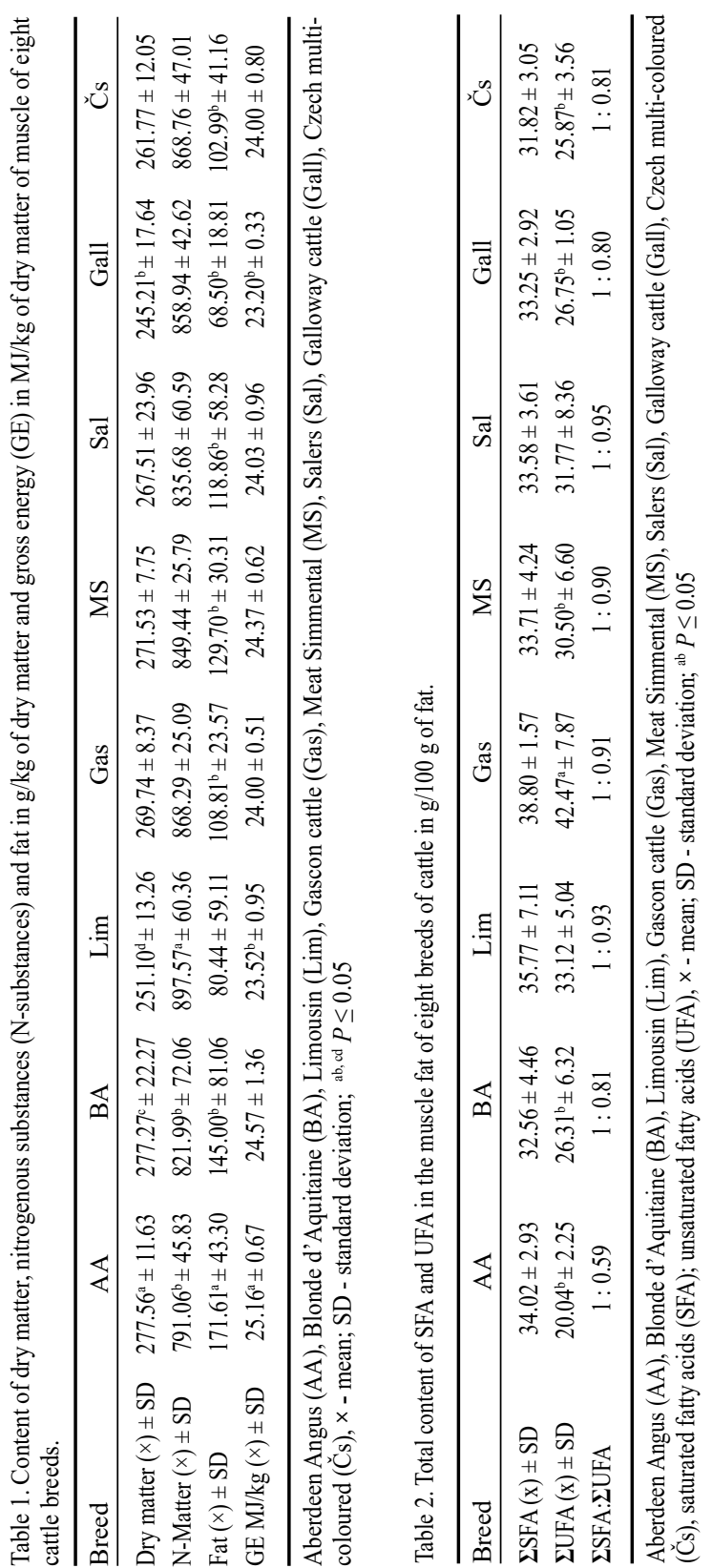

The level of nitrogenous substances were the lowest in AA $(791.1 \pm 45.83 \mathrm{~g} / \mathrm{kg}$ of dry matter). The highest values were discovered in Lim (897.6 \pm 60.36 $\mathrm{g} / \mathrm{kg}$ of dry matter).

The highest content of fat was found in the AA muscle (171.6 \pm $43.30 \mathrm{~g} / \mathrm{kg}$ dry matter), which also had the highest content of gross energy (GE) among the monitored breeds $(25.1 \pm 0.67 \mathrm{MJ} / \mathrm{kg})$. In contrast, the lowest GE value was found in Gall $(23.2 \pm 0.33 \mathrm{MJ} / \mathrm{kg})$.

Total content of saturated and unsaturated FA in the muscle fat

The total content of saturated fatty acids ( $\Sigma$ SFA) ranged from $31.8 \pm$ $3.05 \mathrm{~g}(\check{C} s)$ to $38.8 \pm 1.57 \mathrm{~g}$ (Gas) per $100 \mathrm{~g}$ of fat. The total content of unsaturated fatty acids ( $\Sigma$ UFA) ranged from $20.0 \pm 2.25 \mathrm{~g}$ (AA) to $42.4 \pm 7.87 \mathrm{~g}$ (Gas) per $100 \mathrm{~g}$ of fat. While no significant differences in the values of $\Sigma$ SFA were proven in the monitored breeds, several significant $(\mathrm{P} \leq 0.05)$ to highly significant $(\mathrm{P} \leq 0.01)$ differences were confirmed for $\Sigma$ UFA (Table 2).

Total content of MUFA and PUFA in the muscle fat

Of the unsaturated FA, MUFA predominates, ranging from 5.5 $\times(\mathrm{Lim})$ to $8.9 \times(\mathrm{Sal})$ more in comparison with PUFA (Table 3) in the muscle fat. The total content of MUFA ranges from 17.0 \pm 2.26 $\mathrm{g}$ in AA to $33.8 \pm 3.61 \mathrm{~g}$ in Gas per $100 \mathrm{~g}$ of fat. PUFA had a total presence ranging from $3.0 \pm 1.42$ $\mathrm{g}$ (AA) to $5.1 \pm 3.99 \mathrm{~g}$ (Lim) per $100 \mathrm{~g}$ of fat. 


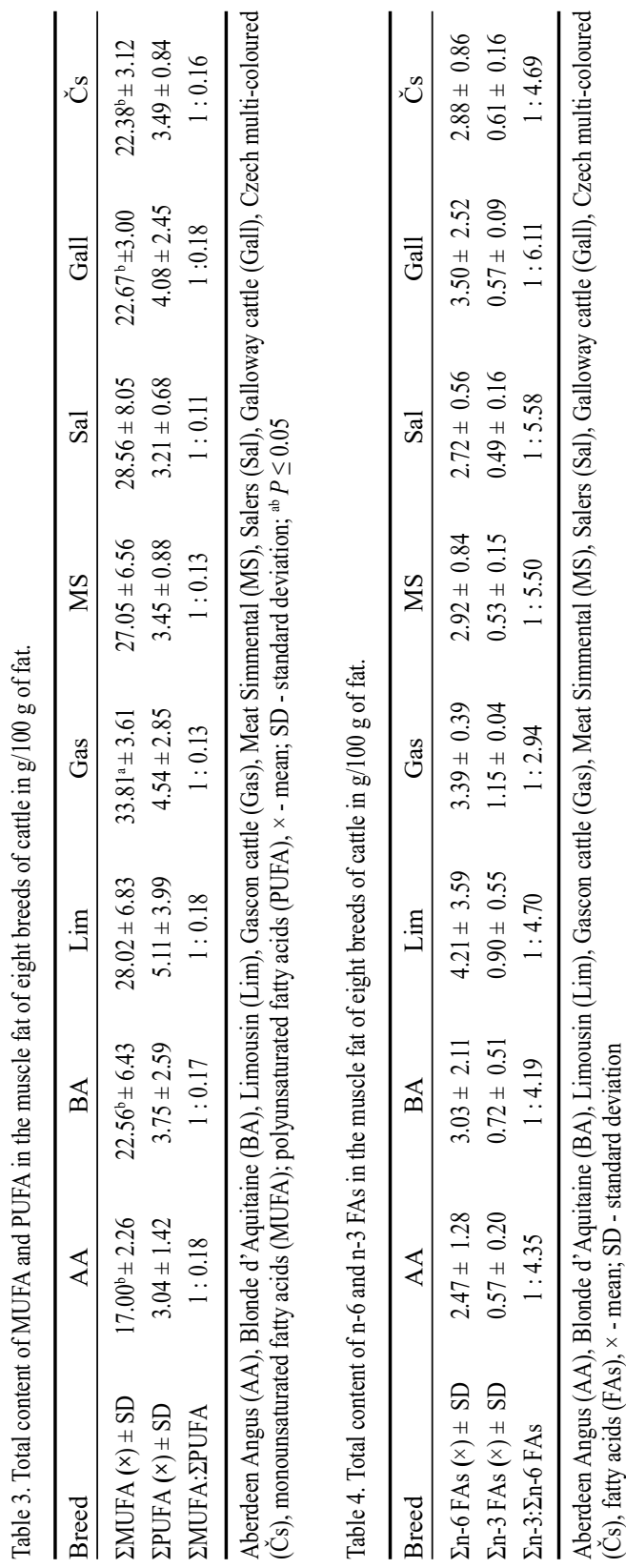

Total content of n-6 and n-3 fatty acids in the muscle fat

The total content of n- 6 FA ranged from $2.4 \pm 1.28 \mathrm{~g}(\mathrm{AA})$ to $4.2 \pm 3.59 \mathrm{~g}$ (Lim) per $100 \mathrm{~g}$ of fat.

The total content of n-3 FA varied from $0.5 \pm 0.16 \mathrm{~g}$ (Sal) to $1.1 \pm 0.04 \mathrm{~g}$ (Gas) per $100 \mathrm{~g}$ of fat in the monitored breeds (Table 4). The ratio of $n-6 / n-3$ ranged from 2.94 (GAS) to 6.11 (Gall).

\section{Discussion}

Presence of essential nutrients in the muscle

Findings on the presence of essential nutrients (dry matter, N-substances, fat), gross energy and especially individual FA in the muscles of bulls of several beef cattle breeds kept under the same conditions are uncommon. However, the values of these indicators may predetermine the biological, dietary and culinary value of the meat.

Wood et al. (2008) give a value of 3.13 $\mathrm{g} / 100 \mathrm{~g}$ for total lipids of the original dry matter in the $\mathrm{m}$. longissimus thoracis of AA breed bulls, aged 19 months and fed a concentrate-based diet. In our case, the value of fat for some breeds was higher (AA, BA, MS), for others it was lower (Lim, Gas, Gall, Čs), and for Salers it was identical.

From the results of the presented analysis (Table 1), we can infer that nutritionally speaking, the muscle of a bull is primarily an important source of protein. However, significant differences were discovered among the breeds. The highest values of nitrogenous substances were discovered in Lim (897.6 \pm $60.36 \mathrm{~g} / \mathrm{kg}$ of dry matter). From this viewpoint, this breed can be evaluated as having the highest muscle quality.

Bull muscle also has a high energy value (GE). This finding is primarily determined by the content of fat, as a highly energetic nutrient. Therefore, the energy level corresponds with the content of muscle fat. The highest fat content was found in the AA muscle $(171.6 \pm 43.30 \mathrm{~g} / \mathrm{kg}$ dry matter), which also had the highest content of energy among the monitored breeds $(25.1 \pm 0.67 \mathrm{MJ} / \mathrm{kg})$. In contrast, the lowest value of GE was discovered in Gall $(23.2 \pm 0.33 \mathrm{MJ} / \mathrm{kg})$. 
Total content of saturated and unsaturated FA in the muscle fat

For consumers, the effect of diet on health and disease prevention is related to their interest in food containing bioactive substances, and in terms of fats, the content of fatty acids. Based on the presence of individual groups of FA in the muscle fat of the eight monitored breeds of cattle, its quality and dietary features may be assessed.

While no significant differences in the values of $\Sigma$ SFA were proven in the monitored breeds, several significant $(P \leq 0.05)$ differences were confirmed for $\Sigma$ UFA (Table 2). For all the monitored breeds, with the exception of Gas, there was a higher presence of SFA compared to UFA. As Kameník (2014) claims, hydrogenation of UFA and SFA occurs in ruminants as a result of first stomach digestion, which also influences the composition of somatic lipids and their consistency. A high content of SFA in the meat of bulls raised on pastures is also documented in the results published by Garcia et al. (2008).

A different ratio between UFA and SFA (Table 2) was shown among the breeds. In Gas, this ratio was 1:1.09, meaning that the fat had an almost equal presence of SFA and UFA. In AA, the content of SFA was almost double the content of UFA (ratio 1:0.59).

\section{Total content of MUFA and PUFA in the muscle fat}

Of the unsaturated FA, MUFA predominated, ranging from $5.4 \times(\mathrm{Lim})$ to $8.9 \times(\mathrm{Sal})$ more in comparison with PUFA (Table 3 ) in the muscle fat. The work of Garcia et al. (2008) and Xie et al. (2012) warns of the high content of MUFA in beef meat.

Muscle fat contained the most acids $\mathrm{C} 18: \ln 9 \mathrm{c} / \mathrm{C} 18: \ln 9 \mathrm{t}$ (oleic/elaidic acid) from the MUFA group. In the significant $\Sigma$ MUFA: $\Sigma$ PUFA ratio, MUFA predominates over PUFA by a ratio of 1:0.11 (Sal) to 1:0.18 (Lim and Gall). Xie et al. (2012) observed the presence of fatty acids in five cattle breeds and reported a significantly higher presence for MUFA (from 26.78 to $36.02 \mathrm{mg} / \mathrm{g}$ ) compared to PUFA (from 5.05 to $6.96 \mathrm{mg} / \mathrm{g}$ ), which corresponds with our findings.

Of the PUFA group, n- 6 FA were most present in the muscle fat, compared to the n-3 PUFA group of fatty acids. From the n- 6 FA group, the muscle fat contained the most linoleic /linolelaidic acid (C18:2n6c/C18:2n6t).

Total content of n- 6 and n-3 fatty acids in the muscle fat

The total content of $\mathrm{n}-3$ PUFA varied in the monitored breeds from $0.5 \pm 0.16 \mathrm{~g}$ (Sal) to $1.1 \pm 0.04 \mathrm{~g}$ (Gas) per $100 \mathrm{~g}$ of fat (Table 4). Somewhat higher $\mathrm{n}-3$ PUFA values ranging from 1.35 to $2.57 \mathrm{~g}$ were observed by Garcia et al. (2008), primarily in bulls on pasture, compared to those grazed with a supplement of corn grain in their diet or those fed a concentrate without access to pasture.

The ratio of $n-6 / n-3$ ranges from 2.94 (GAS) to 6.11 (Gall). In the Holstein and Simmental breeds, Dannenberger et al. (2003) recorded an n-6/n-3 ratio of 1.68 to 2.03. Xie et al. (2012) observed the presence of n-6 and n-3 PUFA in five cattle breeds and recorded significant differences in the presence both of n-6 (4.35-4.98: $6.19 \mathrm{mg} / \mathrm{g})$ and $\mathrm{n}-3$ fat $(0.31-0.39: 0.8 \mathrm{mg} / \mathrm{g})$, which complies with our results. It is obvious that the presence of the n-3 PUFA group is significantly lower in the muscle fat of the monitored breeds. Wood et al. (2004) state that the meat of ruminants is a relatively good source of n-3 PUFA with regard to the presence of 18:3 in the grass. A further increase is possible in animals when incorporating linseed or linseed oil, provided it is "protected" against biodegradation. Efforts to increase the presence of PUFA in the meat of ruminants by providing a diet rich in n-3 FA are also described by Raes et al. (2004).

In terms of dietary health, the relationship between $\Sigma$ n-6: $\Sigma$ n-3 fatty acids is often monitored. A 1:5 ratio is considered optimal. The narrower the ratio is, the higher the quality of the evaluated fat. In the scope of the monitored meat breeds of cattle, the $\Sigma$ n-6: $\Sigma$ n-3 ratio ranged from 1:2.94 (Gas) to 1:6.11 (Gall). That is, for a specific breed, 
there were 3 to 6 times more $\Sigma$ n-6 PUFA than $\Sigma$ n-3 PUFA in the fat. The requirement for a higher intake of polyunsaturated fatty acids in human food (Griel et al. 2006; KrisEtherton 2007) is fulfilled by the Gascon breed (1:2.94). The values were significantly higher $(1: 4.19$ to $1: 6.11)$ in other breeds.

The composition of FA in fatty muscle tissue has a large impact on the meat quality. It determines the strength/oiliness of fat tissue and the meat's oxidation stability, which has an influence on its taste and colour (Wood et al. 2008). Several studies comparing several breeds were done in order to determine the presence of FA in fats in modern cattle breeds (Wood et al. 2004; Garcia et al. 2008; Xie et al. 2012). However, our monitored set of eight breeds is completely exceptional in that multiple modern breeds of beef cattle coming from one location and the same husbandry practices were compared. The different genotypes of the cattle, raised extensively by grazing under the same geographic conditions, influenced the chemical composition of the fat component (especially the presence of individual groups of FA) in the muscle of the slaughtered bulls.

The indicators we studied help predict the biological, dietetic and culinary value of the meat. The results confirmed our hypothesis that within the selected beef cattle breeds there are intermediate differences in the nutritional value of the muscles. Considering the results, it can be generally concluded that dietetically, meat from beef cattle is a high quality food for its substantial content of nutritionally high quality fats, based on the content of different fatty acid groups and their relative proportions.

\section{References}

Aldai N, Dugan MER, Najera AI, Osoro K 2008: N-6 and n-3 fatty acids in different beef adipose tissues depending on the presence or absence of the gene responsible for double-muscling. Czech J Anim Sci 53: 515-522

Alfaia CPM, Alves SP, Martins SIV, Costa ASH, Fontes CMGA, Lemos JPC, Bessa RJB, Prates JAM 2009: Effect of the feeding system on intramuscular fatty acids and conjugated linoleic acid isomers of beef cattle, with emphasis on their nutritional value and discriminatory ability. Food Chem 114: 939-946

Association of Official Analytical Chemists 2006: Official methods of analysis of AOAC International. 17 $7^{\text {th }}$ edn. Association of Analytical Communities, Gaithersburg, USA, 2200 p.

ČSN EN ISO 12966-1. Animal and vegetable fats and oils - Gas chromatography of fatty acid methyl esters - Part 1: Guideline for advanced gas chromatography of fatty acid methyl esters

ČSN EN ISO 12966-2. Animal and vegetable fats and oils - Gas chromatography of fatty acid methyl esters - Part 2: Preparation of fatty acid methyl esters

Daley CA, Abbott A, Doyle PS, Nader GA, Larson S 2010: A review of fatty acid profiles and antioxidant content in grass-fed and grain-fed beef. Nutr J 9: 10

Dannenberge D, Nuernberg K, Nuernberg G, Ender K 2003: Influence of feeding on meat quality and fatty acid composition in beef. Arch Anim Breed 46: 162

Duynisveld JL, Charmley E, Mir P 2006: Meat quality and fatty acid composition of pasture-finished beef steers fed barley and soybeans. Can J Anim Sci 5: 535-554

Enser M, Hallett KG, Hewett B, Fursey GAJ, Wood JD, Harrington G 1998: Fatty acid content and composition of UK beef and lamb muscle in relation to production system and implications for human nutrition. Meat Sci 49: $329-341$

Garcia PT, Pensel NA, Sancho AM, Latimori NJ, Kloster AM, Amigone MA, Casal JJ 2008: Beef lipids in relation to animal breed and nutrition in Argentina. Meat Sci 79: 500-508

Griel AE, Kris-Etherton PM 2006: Beyond saturated fat: The importance of the dietary fatty acid profile on cardiovascular disease. Nutr Rev 64: 257-262

Hara A, Radin NS 1978: Lipid extraction of tissues with a low-toxicity solvent. Analytical Biochemistry 90: 420-426

Holló G, Csapó J, Tözsér J, Holló I, Szücs E 2001: Effect of breed, live weight on the fatty acid, amino acid content and on the biological value of beef. Acta Alim 30: 313-322

Ingr I 2011: Meat Production and Processing (in Czech). Mendelova universita, Brno, 202 p.

Jiang T, Busboom JR, Nelson ML, Mengarelli R 2011: Omega-3 fatty acids affected human perception of ground beef negatively. Meat Sci 89: 390-399

Kameník J 2014: Maso jako potravina: produkce, složení a vlastnosti masa. Veterinární a farmaceutická univerzita, Brno, 327 p. (in Czech)

Kris-Etherton PM, Innis S 2007: Dietary fatty acids - position of the American Dietetic Association and Dietitians of Canada. American Dietetic Association Position Report. J Amer Diet Assoc 107: 1599-1611 
Liu T, Lei ZM, Wu JP, Brown MA, Liu T, Lei ZM, Wu JP 2015. Fatty acid composition differences between adipose depot sites in dairy and beef steer breeds. J Food Sci Tech 52: 1656-1662

Ponnampalam EN, Mann NJ, Sinclair AJ 2006: Effect of feeding systems on omega-3 fatty acids, conjugated linoleic acid and trans fatty acids in Australian beef cuts: Potential impact on human health. Asia Pac J Clin Nutr 15: 21-29

Raes K, De Smet S, Demeyer D 2004: Effect of dietary fatty acids on incorporation of long chain polyunsaturated fatty acids and conjugated linoleic acid in lamb, beef and pork meat: A review. Anim Feed Sci Tech 113: 199-221

Scollan N, Hocquette JF, Nuernberg K, Dannenberger D, Richardson I, Moloney A 2006: Innovations in beef production systems that enhance the nutritional and health value of beef lipids and their relationship with meat quality. Meat Sci 74: 17-33

Smith SB, Gill CA, Lunt DK, Brooks MA 2009: Regulation of fat and fatty acid composition in beef cattle. Asian Austral J Anim Sci 22: 1225-1233

Steinhauser L 2000: Meat Production (in Czech). Steinhauser - Last, Tišnov, 464 p.

Turner TD, Jensen J, Pilfold JL, Prema D, Donkor KK, Cinel B, Thompson DJ, Dugan MER, Church JS 2015: Comparison of fatty acids in beef tissues from conventional, organic and natural feeding systems in western Canada. Can J Anim Sci 95: 49-58

Wood JD, Enser M, Fisher AV, Nute GR, Sheard PR, Richardson RI, Hughes SI, Whitting FM 2008: Fat deposition, fatty acid composition and meat quality: A review. Meat Sci 78: 343-358

Wood JD, Richardson RI, Nute GR, Fisher AV, Campo MM, Kasapidou E, Sheard PR, Enser M 2004: Effects of fatty acids on meat quality: a review. Meat Sci 66: 21-32

Xie X, Meng Q, Cui Z, Ren L 2012: Effect of cattle breed on meat quality, muscle fiber characteristics, lipid oxidation and fatty acids in China. Asian Austral J Anim Sci 25: 824-831

Yüksel S, Yanar M, Aksu MI, Kopuzlu S, Kaban G, Sezgin E, Oz F 2012: Effects of different finishing systems on carcass traits, fatty acid composition, and beef quality characteristics of young Eastern Anatolian Red bulls. Trop Anim Health Prod 44: 1521-1528 